\title{
Simulação e Validação de Parâmetros da Cinética Digestiva em Novilhos Mestiços Suplementados a Pasto, por Intermédio do Sistema In Vitro de Produção de Gases
}

\author{
Edenio Detmann ${ }^{1}$, Mário Fonseca Paulino², Luciano da Silva Cabral ${ }^{3}$, Sebastião de Campos \\ Valadares Filho ${ }^{4}$, Paulo Roberto Cecon ${ }^{5}$, Joanis Tilemahos Zervoudakis ${ }^{3}$, Rogério de Paula \\ Lana ${ }^{6}$, Maria Ignez Leão ${ }^{7}$, André José Nunes Melo ${ }^{8}$
}

\begin{abstract}
RESUMO - Objetivou-se simular e validar a degradação ruminal dos carboidratos e o fluxo nitrogenado microbiano, estimados a partir de parâmetros da cinética de degradação ruminal de amostras de extrusa esofágica e de suplementos obtidos pela técnica in vitro de produção de gases. As estimativas in vivo foram obtidas em experimento de campo, no qual foram utilizados cinco novilhos mestiços Holandês $\mathrm{x}$ Zebu com idade e peso médios iniciais de 24 meses e $304 \mathrm{~kg}$, manejados em cinco piquetes de $B$. decumbens ( 0,34 ha). Foram fornecidos suplementos (4 kg/animal/dia) constituídos por fubá de milho, grão de soja integral, uréia, sulfato de amônia e mistura mineral, formulados para apresentarem níveis de 12, 16, 20 e 24\% de proteína bruta, com base na matéria natural. O experimento foi conduzido em quatro períodos experimentais de 21 dias, em delineamento em quadrado latino 4 x 4 . O quinto animal foi mantido sem suplementação, sendo utilizado como medida de comparação descritiva. A avaliação estatística foi feita por meio do ajustamento de equação de regressão linear simples de valores preditos in vitro sobre valores observados in vivo. A utilização das taxas de digestão específica obtidas in vitro implicou em sub e superestimação da degradação ruminal de carboidratos fibrosos (CF) e não-fibrosos (CNF), cujos vícios globais do processo de de estimação foram de $-25,27 \%$ e $+33,58 \%$, respectivamente. Os valores preditos de eficiência microbiana não mostraram relação significativa com os valores observados, refletindo falta de relação entre valores preditos e observados para o fluxo abomasal de nitrogênio microbiano. A avaliação de alimentos separadamente subestima a taxa de digestão específica de CF.
\end{abstract}

Palavras-chave: capim-braquiária, carboidratos fibrosos, carboidratos não-fibrosos, eficiência microbiana, taxa de degradação

\section{Simulation and Validation of Digestive Kinetic Parameters Using an In Vitro Gas Production System in Crossbred Steers with Pasture Supplementation}

\begin{abstract}
The objective of this trial was simulate and validate the ruminal degradation of carbohydrates and the flow of microbial nitrogen, estimated from samples of esophageal extrusa and supplements, using an in vitro gas production technique. In vivo estimates were obtained from five Holstein x Zebu steers averaging $304 \mathrm{~kg}$ of body weight and 24 months of age that were grazing on five paddocks of Brachiaria decumbens ( $0.34 \mathrm{ha}$ ). The supplements fed to the steers (4 kg/animal/day) contained: grounded corn, whole soybean, urea, ammonium sulfate, and mineral salt and the following crude protein levels: $12,16,20$, or $24 \%$ on as-fed basis. Statistical analyses were performed as a 4 x 4 Latin square design with 21-days periods. The fifth animal was not supplemented and was used only for descriptive comparisons. Data were obtained by regression of values predicted in vitro on values observed in vivo. Use of digestion rates obtained in vitro resulted in under- and over-estimation of the ruminal degradation of fiber (FC) and nonfiber (NFC) carbohydrates with overall biases of $-25.27 \%$ and $+33.58 \%$, respectively. No significant relationship was found between predicted versus observed values for microbial efficiency showing lack of relationship between predicted and observed values for the abomasum flow of microbial nitrogen. Results showed that the ruminal incubation of feeds separately underestimates the digestion rate of FC.
\end{abstract}

Key Words: degradation rate, fiber carbohydrates, nonfiber carbohydrates, microbial efficiency, signalgrass

\section{Introdução}

No atual enfoque da nutrição de ruminantes, a área relativa à avaliação de alimentos vem se destacando quanto à evolução dos métodos e dos conceitos aplicados à determinação da potencialidade e efetividade das dietas ofertadas aos animais. Essas características agregam ao conceito moderno de pecuária de precisão, em que respostas produtivas devem ser previstas, impostas e contabilizadas o mais acuradamente possível.

\footnotetext{
${ }^{1}$ Zootecnista, D.Sc., Professor Adjunto, Departamento de Zootecnia, Universidade Federal de Viçosa, Viçosa-MG, 36571-000, Bolsista do CNPq (detmann@ufv.br).

2 Eng $^{\circ}$. Agrônomo, D.Sc., Professor Adjunto, DZO-UFV, Bolsista do CNPq.

3 Zootecnista, D.Sc., Professor Adjunto, Universidade Federal de Mato Grosso, Cuiabá-MT.

4 Zootecnista, D.Sc., Professor Titular, DZO-UFV, Bolsista do CNPq.

5 Eng ${ }^{\circ}$. Agrônomo, D.Sc., Professor Adjunto, Departamento de Informática-UFV, Bolsista do CNPq.

6 Zootecnista, Ph.D., Professor Adjunto, DZO-UFV, Bolsista do CNPq.

${ }^{7}$ Méd. Veterinária, D.Sc., Professora Titular, DZO-UFV.

8 Zootecnista, Estudante de Mestrado, Universidade Federal de Goiás, Goiânia-GO.
} 
Desta forma, a determinação do valor nutricional dos alimentos envolve estudos que avaliam, conjuntamente, o consumo, a digestibilidade e os parâmetros do metabolismo animal. Contudo, considerando-se que o consumo é fortemente influenciado por inúmeros fatores alheios àqueles que caracterizam o alimento (Mertens, 1994), a avaliação da digestibilidade torna-se principal alvo de estudos, visando determinar as características inerentes aos alimentos.

Embora a avaliação dos parâmetros digestivos dos alimentos possa ser realizada pelos métodos in vitro, in situ ou in vivo, as técnicas in situ e in vivo apresentam o inconveniente da manutenção da animais fistulados, o que amplia o labor e os custos dos procedimentos de avaliação. Métodos in vitro sobressaem-se, além da vantagem descrita anteriormente, por apresentarem rapidez e uniformidade físico-química do microambiente de fermentação ao qual os alimentos são submetidos (Malafaia et al., 1988). Segundo Oba \& Allen (1999), a estimação da digestibilidade da porção fibrosa dos alimentos por procedimentos diferentes dos utilizados in vivo evita o confundimento com fatores relacionados às diferenças no tempo de retenção, no consumo de matéria seca e na exposição ao ambiente intestinal.

No entanto, as técnicas in vitro com enfoque gravimétrico tradicionalmente utilizadas apresentam limitações inerentes, como: (1) a mensuração do resíduo fibroso destrói a amostra, fazendo com que uma nova amostra seja exigida para cada tempo de avaliação; (2) a avaliação nos estágios iniciais de digestão é trabalhosa, em virtude da pequena variação no peso dos resíduos; (3) o papel dos componentes solúveis não pode ser determinado; e (4) quantidades relativamente grandes de amostras são necessárias, gerando dificuldades na avaliação de materiais disponíveis de forma limitada (Pell \& Schofield, 1993).

Como alternativa aos procedimentos gravimétricos, técnicas com enfoque metabólico, que priorizam os produtos da fermentação em detrimento ao substrato residual, permitem contornar os entraves descritos anteriormente. Neste contexto, a mensuração dos gases resultantes da fermentação microbiana permite a predição de parâmetros da cinética digestiva ruminal dos carboidratos, tanto fibrosos como não-fibrosos (Schofield et al., 1994; Schofield \& Pell, 1995), atuando sobre as pressuposições de que a degradação anaeróbia microbiana destes componentes produz, primariamente, dióxido de carbono, metano e ácidos graxos voláteis (Schofield \& Pell, 1995) e de que estes compostos se concentram no meio de forma diretamente proporcional ao desaparecimento do substrato (Schofield et al., 1994).

A avaliação comparativa de alimentos pela técnica de produção de gases ainda é recente em condições brasileiras (Malafaia et al., 1998; Cabral et al., 2000). No entanto, estudos envolvendo a relação de parâmetros obtidos in vitro sobre projeções do comportamento digestivo dos alimentos in vivo são escassos, devendo, portanto, ser enfocados para que se possa verificar a validade e confiabilidade dessas estimativas.

Neste contexto, uma vez que os ruminantes domésticos no Brasil estão submetidos a condições dietéticas em que as pastagens são a principal fonte de nutrientes, a obtenção de estimativas das dinâmicas ruminal e pósruminal desses animais e a verificação do valor nutritivo predito a partir dessas estimativas tornam-se necessidades prementes para o uso dos modernos sistemas de avaliação de alimentos e das exigências nutricionais para esses animais (Vieira et al., 2000).

Neste estudo, objetivou-se simular e validar estimativas de degradação ruminal dos carboidratos, de eficiência de síntese microbiana e de fluxo nitrogenado microbiano abomasal, obtidas por meio de parâmetros da cinética de produção de gases in vitro dos alimentos em novilhos mestiços suplementados, manejados em pastagem de Brachiaria decumbens.

\section{Material e Métodos}

O experimento foi realizado no município de Capinópolis, localizado na macrorregião do Pontal do Triângulo no estado de Minas Gerais. A área experimental consistiu de cinco piquetes de Brachiaria decumbens Stapf. (0,34 ha cada um), providos de bebedouro e comedouro.

Foram fornecidos suplementos constituídos de fubá de milho, soja grão integral, uréia, sulfato de amônia e mistura mineral, balanceados, segundo análise prévia, para apresentarem os níveis de 12, 16, 20 e 24\% de PB, com base na matéria natural. Fixou-se em 3:1 a relação entre os compostos nitrogenados oriundos de alimentos concentrados e aqueles originados da mistura uréia/ sulfato de amônia (9:1). Os suplementos foram fornecidos diariamente na quantidade de $4 \mathrm{~kg} /$ animal às $10 \mathrm{~h}$, proporcionando-se acesso irrestrito à água e à mistura mineral em todos os tratamentos. Paralelamente, foi instalado tratamento controle, no qual se forneceu exclusivamente mistura mineral. 
Foram utilizados cinco novilhos não-castrados $1 / 2$ Holandês $x$ Zebu, com idade e peso médios iniciais de 24 meses e $304 \mathrm{~kg}$, fistulados no esôfago, rúmem e abomaso. O experimento constou de quatro períodos experimentais (cada um com 21 dias de duração, sendo os sete primeiros destinados à adaptação dos animais), conduzidos entre agosto e novembro de 2000.

A avaliação da composição da dieta ingerida pelos animais foi realizada no 5ㅇ e $21^{\circ}$ dias de cada período experimental utilizando-se amostras de extrusa esofágica, conforme especificações de Detmann et al. (2005).

Do $8^{\circ}$ ao $13^{\circ}$ dia do período experimental, realizaram-se coletas de digesta abomasal, que serviram como base para estimação dos compostos degradados no rúmen e da síntese de proteína microbiana. A amostragem seguiu a distribuição: $8 \underline{0}$ dia $-18 \mathrm{~h}, 9 \underline{\mathrm{o}}$ dia $-16 \mathrm{~h}, 10^{\circ}$ dia $-14 \mathrm{~h}, 11^{\circ}$ dia $-12 \mathrm{~h}, 12^{\circ}$ dia -10 h e $13^{\circ}$ dia -8 h. Após secagem em estufa de ventilação forçada $\left(60^{\circ} \mathrm{C}-72\right.$ horas $)$, as amostras foram processadas em moinho do tipo Willey ( $1 \mathrm{~mm})$ e compostas proporcionalmente, com base no peso seco ao ar, por animal/período e armazenadas em frascos de polietileno para posterior análise.

Ao $14^{\circ}$ dia do período experimental, realizou-se coleta de líquido ruminal com o objetivo de isolar microrganismos ruminais, imediatamente antes e 6 horas após o fornecimento dos suplementos, conforme técnica descrita por Cecava et al. (1990). As amostras foram acondicionadas em frascos de polietileno e congeladas a $-20^{\circ} \mathrm{C}$ após a adição de formaldeído (PA), na proporção de $10 \mathrm{~mL} / \mathrm{L}$, como agente conservante.

A estimação da excreção fecal e da cinética de trânsito de partículas baseou-se no fornecimento de indicador externo, em dose única (France et al., 1988), empregando-se como indicador o cromo mordentado à fibra, produzido conforme descrição de Udén et al. (1980). A base fibrosa para produção do indicador foi retirada de amostras de simulação manual de pastejo, obtidas entre o 5 o e o $10^{0}$ dias de cada período experimental. Para simulação do processo inicial de mastigação, as amostras de pastejo simulado foram submetidas a um processo tríplice de moagem em moinho tipo Willey, sem a presença de peneira. Foram fornecidos, por animal, $100 \mathrm{~g}$ de fibra mordentada no $16^{\mathrm{o}}$ dia do período experimental, às $8 \mathrm{~h}$. As amostras fecais foram tomadas nos tempos $0,6,12,18,24,30$, $36,42,48,60,84,108$ e 144 horas após o fornecimento do indicador (Detmann et al., 2001), sendo, posteriormente, secas em estufa de ventilação forçada $\left(60^{\circ} \mathrm{C}\right.$ - 72 horas), processadas em moinho tipo Willey ( $1 \mathrm{~mm}$ ) e acondicionadas individualmente em frascos de polietileno. Em seguida, foram retiradas de cada amostra alíquotas de $3 \mathrm{~g}$, elaborando-se amostras compostas por animal/período.

Posteriomente, as amostras de fezes e de fibra mordentada foram analisadas individualmente quanto aos teores de matéria seca (AOAC, 1990) e cromo (Willians et al., 1962). Ajustou-se às curvas de excreção fecal do indicador o modelo não-linear, gama 2, tempo-dependente (France et al., 1988):

$$
C_{t}=Z(t-\tau) L^{2} \exp [-L(t-\tau)]
$$

em que: $\mathrm{Ct}=$ concentração fecal do indicador no tempo " $t$ " (ppm); $t=$ tempo após o fornecimento do indicador (horas); $\mathrm{L}$ = parâmetro taxa tempo-dependente relativo ao fluxo ruminal de partículas $\left(\mathrm{h}^{-1}\right)$; $\mathrm{Z}$ = parâmetro sem interpretação biológica direta (ppm.h); e $\tau=$ tempo decorrido entre a aplicação e o aparecimento do indicador nas fezes (h).

A excreção diária de matéria seca fecal foi estimada pela equação (France et al., 1988):

$$
E F=(D / Z) \times 24
$$

em que: $E F$ = excreção fecal $(\mathrm{kg} /$ dia $) ; \mathrm{D}=$ dose de cromo (mg); e Z como definido anteriormente.

As projeções de consumo e fluxo abomasal de matéria seca foram obtidas por meio da relação entre excreção fecal diária e concentrações dietética e abomasal de FDN indigestível (Lippke et al., 1986; Detmann et al., 2005).

As amostras de suplementos, compostas fecais e abomasais e extrusas foram avaliadas quanto aos teores de MS, MO, PB, extrato etéreo (EE), cinzas (AOAC, 1990) e FDN (Van Soest \& Robertson, 1985) (Tabela 1).

A quantificação da biomassa microbiana nas amostras do rúmen e do abomaso foi feita utilizando-se as bases púricas como indicadores (Ushida et al., 1985). A eficiência de síntese microbiana foi expressa pela unidade $\mathrm{g}$ de MS microbiana por $\mathrm{kg}$ de carboidratos totais degradados no rúmen (CTDR) (Russell et al., 1992).

Para os procedimentos de estimação da produção cumulativa de gases, foram tomadas de amostras de extrusa esofágica e de suplementos duas alíquotas de aproximadamente $100 \mathrm{mg}$, as quais foram acondicionadas em frascos de vidro com $50 \mathrm{~mL}$ em volume total, 
aos quais foram imediatamente adicionados $8 \mathrm{~mL}$ de solução tampão de McDougall (McDougall, 1949) com pH previamente ajustado em 6,8 por meio de aspersão com $\mathrm{CO}_{2}$ por aproximadamente 20 minutos. Os frascos foram acondicionados em sala climatizada $\left(39^{\circ} \mathrm{C}\right)$ por 30 minutos, para estabilização da temperatura e hidratação das amostras. Durante esse processo, procedeu-se à coleta de líquido ruminal de um novilho mestiço fistulado no rúmen e alimentado com feno de Brachiaria brizantha e concentrado na proporção de 70:30, respectivamente. O líquido, após filtragem em camada tríplice de gaze, foi acondicionado em recipiente térmico e imediatamente conduzido ao local de incubação.

Foram adicionados $2 \mathrm{~mL}$ do inóculo ruminal aos frascos que continham as amostras e a solução tampão, procedendo-se imediatamente à vedação com tampas de borracha e lacres de alumínio. Os frascos foram, então, dispostos sobre mesa com agitação orbital.
As leituras foram realizadas $1,2,3,4,5,6,8,10$, $12,15,24,27,30,33,36,48,56,60,72,96$ e 120 horas após o início da incubação, empregando-se uma agulha de seringa acoplada a um transdutor eletrônico, ligado diretamente a um multímetro. Nesse procedimento, a pressão ao interior dos frascos, formada pelo acúmulo de gases, foi medida com auxílio do transdutor, em unidades elétricas $(\mathrm{mV})$, posteriormente convertidas em volume de gás $(\mathrm{mL})$, pelo procedimento descrito por Pell \& Schofield (1993). Os volumes obtidos nos intervalos de leitura supracitados foram adicionados seqüencialmente, de forma a se obter, em determinado tempo, a produção acumulada de gases.

Às curvas obtidas, submeteu-se, por intermédio do procedimento iterativo de Gauss-Newton, o ajuste do modelo logístico bi-compartimental descrito por Schofield et al. (1994):

$$
V t=V f_{1}\left\{1+\exp \left[2+4 \frac{\mu m_{1}}{V f_{1}}(L-t)\right]\right\}^{-1}+V f_{2}\left\{1+\exp \left[2+4 \frac{\mu m_{2}}{V f_{2}}(L-t)\right]\right\}^{-1}
$$

Tabela 1 - Composição química de extrusa esofágica e de suplementos, com base na matéria seca Table 1 - Chemical composition of esophageal extrusa and supplements on dry matter basis

\begin{tabular}{|c|c|c|c|c|c|c|}
\hline \multirow[b]{2}{*}{ Item $^{1}$} & \multicolumn{2}{|c|}{ Extrusa } & \multicolumn{4}{|c|}{$\begin{array}{l}\text { Suplemento } \\
\text { Supplement }\end{array}$} \\
\hline & $\begin{array}{l}\text { Média } \\
\text { Mean }\end{array}$ & $\begin{array}{l}\mathrm{EPM}^{2} \\
S E M^{2} \\
\end{array}$ & $12 \%$ & $16 \%$ & $20 \%$ & $24 \%$ \\
\hline $\begin{array}{l}\text { MS (\%) } \\
D M(\%)\end{array}$ & 12,82 & 0,168 & 87,03 & 87,34 & 87,37 & 87,68 \\
\hline $\begin{array}{l}\text { Cinzas }^{3} \\
A_{s h^{3}}\end{array}$ & 114,3 & 4,527 & 21,6 & 28,6 & 33,4 & 37,6 \\
\hline $\begin{array}{l}\mathrm{MO}^{3} \\
O M^{3}\end{array}$ & 885,7 & 4,527 & 978,4 & 971,4 & 966,6 & 962,4 \\
\hline $\begin{array}{l}\mathrm{PB}^{3} \\
C P^{3}\end{array}$ & 109,9 & 8,832 & 147,0 & 188,2 & 229,9 & 274,0 \\
\hline $\begin{array}{l}\mathrm{EE}^{3} \\
\mathrm{CT}^{3,4} 4 \\
T C^{3,4}\end{array}$ & $\begin{array}{r}19,2 \\
756,5\end{array}$ & $\begin{array}{r}0,236 \\
10,612\end{array}$ & $\begin{array}{r}48,3 \\
783,1\end{array}$ & $\begin{array}{r}62,3 \\
720,9\end{array}$ & $\begin{array}{r}79,6 \\
657,1\end{array}$ & $\begin{array}{r}84,9 \\
603,5\end{array}$ \\
\hline $\begin{array}{l}\mathrm{FDN}^{3} \\
N D F^{3}\end{array}$ & 564,4 & 14,635 & 74,8 & 80,0 & 87,1 & 98,8 \\
\hline $\begin{array}{l}\mathrm{FDNi}^{3} \\
I N D F^{3}\end{array}$ & 121,0 & 8,348 & 6,3 & 5,9 & 7,7 & 6,8 \\
\hline $\begin{array}{l}\mathrm{CNF}^{3,5} \\
N F C^{3,5}\end{array}$ & 192,1 & 5,835 & 708,3 & 640,8 & 570,0 & 504,7 \\
\hline
\end{tabular}

${ }^{1}$ MS - matéria seca; MO - matéria orgânica; PB - proteína bruta; EE - extrato etéreo; CT - carboidratos totais; FDN - fibra em detergente neutro; FDNi - fibra em detergente neutro indigestível; CNF - carboidratos não-fibrosos.

${ }^{2}$ EPM - erro-padrão da média.

$3 \mathrm{~g} / \mathrm{kg} \mathrm{MS}$.

${ }^{4} \mathrm{CT}=100-(\mathrm{PB}+\mathrm{EE}+$ Cinzas $)$.

${ }^{5} \mathrm{CNF}=\mathrm{CT}-\mathrm{FDN}$.

${ }^{1}$ DM - dry matter; OM - organic matter; CP - crude protein; EE - ether extract; TC - total carbohydrates; NDF - neutral detergent fiber; iDNF - indigestible neutral detergent fiber; NFC - nonfiber carbohydrates.

${ }^{2}$ EM - standard error of mean.

${ }^{3} \mathrm{~g} / \mathrm{kg}$ of $D M$.

$4 T C=100-(C P+E E+A s h)$.

${ }^{5} N F C=T C-N D F$. 
em que: $\mathrm{Vt}=$ volume acumulado de gases no tempo " $\mathrm{t}$ " $(\mathrm{mL}) ; \mathrm{Vf}=$ volume total de gases produzido em $\mathrm{t} \rightarrow \infty(\mathrm{mL}) ; \mu \mathrm{m}=$ taxa máxima de produção de gases $\left(\mathrm{mL} \cdot \mathrm{h}^{-1}\right) ; \mathrm{L}=$ latência $(\mathrm{h}) ; \mathrm{t}=$ tempo após o início da incubação (h); e "1" e "2" (sub-escritos) = indicadores referentes à cinética de produção de gases a partir de $\mathrm{CF}$ e CNF, respectivamente.

A razão $\mu \mathrm{m} / \mathrm{Vf}$ (Equação 3), que apresenta a unidade $h^{-1}$, representa a taxa específica de digestão (kd) do substrato (Schofield et al., 1994), admitida neste estudo como similar à taxa específica de crescimento microbiano sob a pressuposição de relação diretamente proporcional entre o volume de gás produzido, a produção microbiana e o substrato digerido.

A partir da obtenção das taxas específicas de digestão, foram estimados, separadamente para CF e CNF oriundos de extrusa e suplementos, os coeficientes de degradação ruminal, empregando-se as equações (Allen \& Mertens, 1988):

$$
\begin{gathered}
C D R c f e=[k d /(k d+k r)] \times[1+k r /(k d+k e)] \\
C D R=[k d /(k d+k p)]
\end{gathered}
$$

em que: $\mathrm{CDR} c f e=$ coeficiente de degradação ruminal $\left(\mathrm{g} \cdot \mathrm{g}^{-1}\right.$ ) para os CF da extrusa; $\mathrm{CDR}=$ coeficiente de degradação ruminal $\left(\mathrm{g} \cdot \mathrm{g}^{-1}\right)$ para as demais frações de carboidratos; $k d=$ taxa específica de digestão $\left(h^{-1}\right)$; $\mathrm{kr}=$ taxa de escape do pool não-escapável para o pool potencialmente escapável $\left(\mathrm{h}^{-1}\right) ; \mathrm{ke}=$ taxa de escape do pool potencialmente escapável $\left(\mathrm{h}^{-1}\right)$; e kp = taxa passagem considerando cinética de partículas de ordem gama-1 $\left(\mathrm{h}^{-1}\right)$.

A diferença observada entre as equações (4) e (5) decorre do fato de que a cinética de trânsito de partículas oriundas da forragem se baseia em modelo de ordem gama-2 (Equação 1), o qual, embora de natureza unicompartimental, assume a existência de dois pools distintos de partículas no ambiente ruminal (France et al., 1988). O primeiro, relativo a partículas sem características cinéticas que permitam o escape ao trato posterior, o qual fornece, gradativamente, partículas ao segundo pool, as quais são consideradas potencialmente escapáveis. Em razão da natureza unicompartimental do modelo, pressupõe-se que ambas as taxas ( $\mathrm{kr}$ e ke) sejam idênticas e coincidentes ao parâmetro "L" (Equação 1). Para os CNF da extrusa, admitiu-se a não-existência do primeiro pool descrito anteriormente, pressupondo-se cinética de ordem gama-1, parametrizada segundo o parâmetro "L" (Equação 1). Essa pressuposição também foi admitida para as frações de carboidratos originadas dos suplementos, sendo a taxa de escape ruminal, uma vez não utilizado indicador de base não-fibrosa, estimada conforme recomendações do NRC (2001), segundo a equação:

$$
k_{p}\left(h^{-1}\right)=0,02904+0,01375 C M S-0,00020 N C
$$

em que: CMS = consumo de MS (\% do peso vivo); e $\mathrm{NC}=$ nível de concentrado na dieta (\%).

As estimativas da degradação ruminal das frações de carboidratos ( $\mathrm{kg} / \mathrm{dia}$ ) foram tomadas como o produto entre o consumo diário da porção potencialmente degradável de cada fração de carboidratos $(\mathrm{kg})$ e seu respectivo coeficiente de degradação ruminal. As frações de CNF foram consideradas com potencial de degradação ruminal completo; para CF, essa fração foi obtida pela diferença entre os consumos de FDN e FDNi.

A eficiência de síntese microbiana foi estimada segundo proposição de Pirt (1965), conforme a equação:

$$
\frac{1}{Y}=\frac{m}{S g r}+\frac{1}{Y m}
$$

em que: $\mathrm{Y}=$ eficiência microbiana ( $\mathrm{g}$ células $\cdot \mathrm{g}^{-1}$ carboidrato degradado); $\mathrm{m}=$ exigência de mantença das bactérias ( $\mathrm{g}$ carboidrato $\cdot \mathrm{g}^{-1}$ célula $\mathrm{h}^{-1}$ ); $\mathrm{Ym}=$ eficiência teórica máxima dos microrganismos sobre o substrato (g células . $\mathrm{g}^{-1}$ carboidratos); e Sgr = taxa de crescimento específico dos microrganismos sobre o substrato $\left(\mathrm{h}^{-1}\right)$.

As estimativas de eficiência de síntese microbiana foram obtidas individualmente sobre CF e CNF para extrusa e suplementos, sendo, ao final, produzido um valor médio ponderado em função da participação de cada fração sobre o total estimado de carboidratos degradados no rúmen. Adotou-se como referência ao parâmetro Ym o valor de $0,4 \mathrm{~g}$ célula $\mathrm{g}^{-1}$ carboidrato degradado e, para "m", os valores de 0,05 e 0,15 g carboidrato $\mathrm{g}^{-1}$ célula $^{-1}$, para $\mathrm{CF}$ e CNF, respectivamente, conforme especificações de Russell et al. (1992). Os valores obtidos para taxas de digestão específica foram, como ressaltado anteriormente, empregados como estimativas para o parâmetro Sgr.

O fluxo de $\mathrm{N}$ microbiano ao abomaso foi assumido como o produto entre os valores estimados para eficiên- 
cia microbiana, carboidratos totais degradados no rúmen (CTDR) e teor de $\mathrm{N}$ nos microrganismos, adotando-se, para o teor de $\mathrm{N}$ nos microrganismos, os valores observados in vivo.

O experimento foi instalado segundo delineamento quadrado latino balanceado para efeitos residuais de tratamentos (Cochran \& Cox, 1957). Ao tratamento controle, foram destinados o mesmo animal e piquete durante todo o período experimental, utilizados como medida de comparação descritiva em relação ao delineamento.

O procedimento de validação dos parâmetros avaliados foi realizado de forma independente aos tratamentos aplicados, por meio do ajuste de modelo de regressão linear simples (modelo completo) dos valores preditos sobre os valores observados. As estimativas dos parâmetros de regressão foram testadas sob as hipóteses:

$$
\begin{array}{ll}
H_{0}: \beta_{0}=0 & H_{0}: \beta_{1}=1 \\
H_{a}: \beta_{0} \neq 0 & H_{a}: \beta_{1} \neq 1
\end{array}
$$

Em caso de não-rejeição de ambas as hipóteses de nulidade, optou-se pela similaridade entre valores preditos e observados. Em situação contrária, nova equação de regressão foi traçada, suprimindo-se o parâmetro relativo ao intercepto (modelo reduzido), estimando-se o vício global das estimativas como:

$$
B=(\hat{\beta}-1) \times 100
$$

em que: $\mathrm{B}=$ vício global das estimativas $(\%) ; \hat{\beta}=$ estimativa do coeficiente angular da equação ajustada sem a consideração do parâmetro intercepto (modelo reduzido).

Para todos os procedimentos estatísticos empregados, adotou-se $\alpha=0,05$.

\section{Resultados e Discussão}

As estimativas médias das taxas de digestão específica para amostras de extrusa esofágica e suplementos, as médias para valores preditos e observados e os parâmetros das equações de regressão para as variáveis carboidratos totais (CTDR), fibrosos (CFDR) e não-fibrosos (CNFDR) degradados no rúmen, eficiência de síntese microbiana (EFIM) e fluxo de nitrogênio de origem microbiana ao abomaso (NMIC) encontram-se nas Tabelas 2, 3 e 4, respectivamente.
A avaliação estatística dos coeficientes de inclinação das retas no modelo completo para CTDR, CFDR e CNFDR apontou a não-aceitação da hipótese de nulidade para todas as variáveis $(\mathrm{P}<0,01)$ (Tabela 4). Em termos de intercepto, observou-se, para CTDR e CNFDR, a não-aceitação da hipótese de nulidade $(\mathrm{P}<0,01)$, apontando, na relação analisada, a existência de um valor constante somado aos valores preditos de forma independente aos valores observados, o qual pode ser denotado com vício constante (Rayburn \& Fox, 1993). Embora não se rejeitando a hipótese de nulidade sobre a estimativa de intercepto para CFDR $(\mathrm{P}>0,05)$, o comportamento da função ajustada, à semelhança de CTDR e CNFDR, mostrou a não-correspondência entre valores preditos e observados.

Submetendo-se estas variáveis ao ajuste de equação de regressão sem considerar o intercepto, observou-se vício global extremamente reduzido sobre a degradação ruminal dos CT (+0,98\%), o que aparentemente é incoerente ao diagnóstico estatístico obtido com o modelo completo (Tabela 4). Por outro lado, a avaliação das diferentes frações dos carboidratos totais apontou subestimação dos CFDR e superestimação dos CNFDR, que apresentaram vício global de $-25,27$ e $+33,58 \%$, respectivamente. Esse comportamento vicioso pode ser melhor visualizado pela elevada concentração de pontos abaixo e acima da reta de equalidade $(\mathrm{X}=\mathrm{Y})$ para CFDR e CNFDR, respectivamente (Figura 1). Provavelmente, o comportamento oposto dos vícios globais para as diferentes frações de carboidratos ocasionou a tendência de anulação do vício relativo ao total de carboidratos degradados no rúmen, justificando esse comportamento.

Ao conduzir avaliação semelhante à realizada neste estudo, Vieira et al. (2000) encontraram comportamento similar sobre CFDR, relatando, no entanto, vício global de $-70,64 \%$, superior ao descrito neste trabalho. Segundo esses autores, grande parte desta discrepância entre valores preditos e observados seria atribuída a estimativas elevadas da taxa de passagem ruminal dos componentes da forragem, sugerindo que aperfeiçoamentos nos métodos de estimação desse parâmetro poderiam implicar em maior verossimilhança sobre as estimativas de degradação ruminal.

Huhtanen et al. (1995), ao empregarem diferentes combinações de métodos para predição da digestibilidade ruminal da FDN, relataram que a aplicação de conceitos de retenção seletiva sobre a cinética de trânsito de partículas reduziu substancialmente o vício global das estimativas. Embora o modelo 
Tabela 2 - Estimativas médias de taxas de digestão específica $\left(\mathrm{h}^{-1}\right)$ para carboidratos fibrosos (CF) e não-fibrosos (CNF) em amostras de extrusa esofágica e suplementos

Table 2 - Average estimates of the specific digestion rates $\left(h^{-1}\right)$ for fiber (FC) and nonfiber (NFC) carbohydrates in samples of esophageal extrusa and supplements

\begin{tabular}{|c|c|c|c|c|c|c|}
\hline \multicolumn{3}{|c|}{$\begin{array}{c}\text { Extrusa } \\
\text { Esophageal extrusa }\end{array}$} & \multicolumn{4}{|c|}{$\begin{array}{l}\text { Suplemento } \\
\text { Supplement }\end{array}$} \\
\hline & $\begin{array}{l}\text { Média } \\
\text { SEM }\end{array}$ & $\begin{array}{l}\text { EPM } \\
\text { Mean }\end{array}$ & $12 \%$ & $16 \%$ & $20 \%$ & $24 \%$ \\
\hline $\begin{array}{l}\mathrm{CF} \\
F C\end{array}$ & 0,0 & 0,0010 & 0,0295 & 0,0368 & 0,0324 & 0,0354 \\
\hline $\begin{array}{l}\mathrm{CNF} \\
N F C\end{array}$ & 0,1146 & 0,0085 & 0,2299 & 0,1325 & 0,1265 & 0,1258 \\
\hline
\end{tabular}

Tabela 3 - Valores médios preditos e observados para carboidratos totais (CTDR), fibrosos (CFDR) e não-fibrosos (CNFDR) degradados no rúmen, eficiência de síntese microbiana (EFIM) e fluxo abomasal de nitrogênio microbiano (NMIC)

Table 3 - Predicted and observed values for total (RDTC), fiber (RDFC) and nonfiber (RDNFC) ruminal degraded carbohydrates, efficiency of microbial synthesis (EFIM) and abomasum flow of microbial nitrogen (ABMIC)

\begin{tabular}{|c|c|c|}
\hline $\begin{array}{l}\text { Variável } \\
\text { Variable }\end{array}$ & $\begin{array}{l}\text { Valor predito } \\
\text { Estimated value }\end{array}$ & $\begin{array}{l}\text { Valor observado } \\
\text { Observed value }\end{array}$ \\
\hline $\begin{array}{l}\mathrm{CTDR}^{1} \\
\text { RDTC }^{1}\end{array}$ & 4,282 & 3,928 \\
\hline $\begin{array}{l}R D T C^{1} \\
\text { CFDR }^{1} \\
R D F C^{1}\end{array}$ & 2,106 & 2,758 \\
\hline $\begin{array}{l}\text { CNFDR }^{1} \\
\text { RDNFC }\end{array}$ & 2,176 & 1,170 \\
\hline $\begin{array}{l}\text { EFIM }^{2} \\
\text { NMIC }^{3} \\
A B M I C^{3}\end{array}$ & $\begin{array}{r}250,7 \\
73,7\end{array}$ & $\begin{array}{r}316,2 \\
75,9\end{array}$ \\
\hline
\end{tabular}

${ }^{1} \mathrm{~kg} / \mathrm{dia}(\mathrm{kg} / \mathrm{day})$.

${ }^{2} \mathrm{~g}$ MS microbiana/kg CTDR ( $\mathrm{g}$ of microbial DM/kg RDTC).

${ }^{3} \mathrm{~g} / \mathrm{dia}(\mathrm{g} / \mathrm{day})$.

aplicado neste trabalho sobre a fração fibrosa da forragem seja de natureza unicompartimental (France et al., 1988), apresenta estrutura de ordem gama-2, o que implica na introdução de conceitos similares, principalmente pela alteração direta sobre as estimativas dos coeficientes de degradação ruminal dessa fração, como pode ser verificado pela estrutura da Equação (4) em comparação à Equação (5), comumente adotada em estudos da cinética de degradação ruminal (Sniffen et al., 1992). Essa diferença constitui, ao menos em parte, em possível causa da menor amplitude do vício obtido neste estudo em relação ao relatado por Vieira et al. (2000), que realizaram a interpretação da curva de excreção do indicador de base fibrosa pelo procedimento de curve peeling, o que implica em interpretação da cinética de trânsito de partículas com estrutura de ordem gama ${ }^{-1}$.

De modo geral, a grande influência dos parâmetros da cinética de trânsito sobre as estimativas da digestibilidade ruminal, como se observa na estrutura das equações (4) e (5), pode determinar, em muitos casos, a validade ou não de valores simulados. Esses parâmetros podem ter colaborado para o comportamento observado sobre CNFDR. Os concentrados apresentam maior densidade que os alimentos volumosos, o que, em associação ao menor tamanho de partícula, habilita-os a taxas de escape mais elevadas em relação às forragens. Embora o valor médio predito para kp de concentrados $(0,0609 \mathrm{~h}-1)$ encontre-se próximo ao relatado na literatura (Colluci et al., 1990; Bürger et al., 2000), a porção dos CNF relativa a açúcares e amido solúvel apresenta escape ruminal associado à taxa de passagem de líquidos (Djkistra et al., 1996), que é superior à taxa de escape de partículas de concentrados (Bürger et al., 2000). Associando-se a isto o fato de pequenas partículas apresentarem-se suspensas na fração líquida ruminal (Poppi et al., 1981, citados por Hess et al., 1994), justifica-se o quadro de elevação natural na cinética de trânsito de alimentos concentrados, o qual, não sendo considerado, induziria à superestimação do coeficiente de degradabilidade ruminal (Equação 5), justificando, em parte, o comportamento observado neste estudo.

A avaliação das estimativas de EFIM (Tabela 3) apontou não-aceitação de ambas as hipóteses de nulidade $(\mathrm{P}<0,01)$. Embora tenha-se quantificado vício global de -39,73\% (Equação 9), a estimação desse parâmetro não apresenta sentido comparativo, uma vez que o coeficiente de inclinação obtido no modelo completo não diferiu estatisticamente de zero $(\mathrm{P}>0,05)$, indicando completa falta de relação entre valores preditos e observados (Figura 2). Ressalta-se que a equação de Pirt (1965) (Equação 7), empregada neste estudo, não permite considerar variações na cinética de trânsito ruminal, as quais influem consideravelmente na partição da energia entre mantença e crescimento microbiano (Van Soest, 1994). Adicionalmente, não se consideram possíveis alterações na composição microbiana em função de influências do meio de crescimento (Nocek \& Russell, 1988) e interações entre alimentos da dieta no tocante ao fornecimento de substratos limitantes ao crescimento 
Tabela 4 - Estimativas de parâmetros, níveis descritivos de probabilidade para as hipóteses de nulidade e coeficientes de determinação $\left(r^{2}\right)$ para as regressões entre valores preditos e observados para carboidratos totais (CTDR), fibrosos (CFDR) e não-fibrosos (CNFDR) degradados no rúmen, eficiência de síntese microbiana (EFIM) e fluxo abomasal de nitrogênio microbiano (NMIC)

Table 4 - Parameters estimates, descriptive levels of probability for null hypothesis and determination coefficient $\left(r^{2}\right)$ for the regression model among estimated and observed values according the variables total (RDTC), fiber (RDFC) and nonfiber (RDNFC) ruminal degraded carbohydrates, efficiency of microbial synthesis (EFIM) and abomasum flow of microbial nitrogen $(A B M I C)$

\begin{tabular}{|c|c|c|c|c|c|c|}
\hline \multirow[b]{3}{*}{ Item } & \multicolumn{4}{|c|}{$\begin{array}{l}\text { Modelo completo } \\
\text { Complete model }\end{array}$} & \multirow[b]{3}{*}{$r^{2}$} & \multirow[b]{3}{*}{$\begin{array}{l}\text { Vício globa } \\
\text { Overall bia }\end{array}$} \\
\hline & \multicolumn{2}{|c|}{$\begin{array}{l}\text { Intercepto } \\
\text { Intercept }\end{array}$} & \multicolumn{2}{|c|}{$\begin{array}{l}\text { Coeficiente de inclinação } \\
\text { Slope coefficient }\end{array}$} & & \\
\hline & $\begin{array}{c}\text { Estimativa } \\
\text { Estimate }\end{array}$ & $\begin{array}{l}\text { Valor- }{ }^{1} \\
P \text {-Value }\end{array}$ & $\begin{array}{c}\text { Estimativa } \\
\text { Estimate }\end{array}$ & $\begin{array}{l}\text { Valor- } \mathrm{P}^{2} \\
\text { P-Value }^{2}\end{array}$ & & \\
\hline $\begin{array}{l}\mathrm{CTDR}^{3} \\
\text { RDTC }^{3}\end{array}$ & 2,9355 & 0,0002 & 0,3423 & 0,0344 & 0,2255 & $+0,98 \%$ \\
\hline $\begin{array}{l}\mathrm{CFDR}^{3} \\
R D F C^{3}\end{array}$ & 0,4091 & 0,1105 & 0,6151 & 0,0002 & 0,7512 & $-25,27 \%$ \\
\hline $\begin{array}{l}\mathrm{CNFDR}^{3} \\
R D N F C^{3}\end{array}$ & 1,4528 & 0,0005 & 0,4780 & 0,0283 & 0,2476 & $+33,58 \%$ \\
\hline $\begin{array}{l}\text { EFIM }^{4} \\
\text { NMIC }^{5} \\
A B M I C^{5}\end{array}$ & $\begin{array}{r}250,7157 \\
61,2148\end{array}$ & $\begin{array}{l}0,0001 \\
0,0001\end{array}$ & $\begin{array}{l}0,00656 \\
0,16456\end{array}$ & $\begin{array}{l}0,0001 \\
0,0001\end{array}$ & $\begin{array}{l}0,0072 \\
0,1304\end{array}$ & $\begin{array}{l}-39,73 \% \\
-20,25 \%\end{array}$ \\
\hline
\end{tabular}

${ }^{1} \mathrm{H}_{0}: \beta_{0}=0 ;{ }^{2} \mathrm{H}_{0}: \beta_{1}=1 ;{ }^{3} \mathrm{~kg} /$ dia (kg/day); ${ }^{4} \mathrm{~g}$ MS microbiana/kg CTDR ( $\mathrm{g}$ of microbial DM $/ \mathrm{kg}$ of $R D T C$ ); ${ }^{5} \mathrm{~g} /$ dia $(\mathrm{g} /$ day).

microbiano. Estes fatos permitiram que a estimativa média de EFIM predita (250,7 g MS microbiana $/ \mathrm{kg}$ CTDR) se aproximasse mais intensamente dos valores observados em animais não-suplementados (192,7 g MS microbiana/kg CTDR) em detrimento ao observado com o fornecimento de suplementos (347,0 g MS microbiana/ kg CTDR).

Com o objetivo de melhor entender o comportamento de EFIM, conduziu-se o segundo procedimento de avaliação da cinética de produção de gases de forma semelhante ao primeiro, tomando-se, contudo, como substrato ao crescimento microbiano as dietas de forma completa, montadas de acordo com as relações volumoso:concentrado observadas in vivo. As estimativas dos parâmetros cinéticos foram comparadas à projeção ponderada das taxas de digestão específica obtidas com extrusa e suplementos separadamente, de forma semelhante aos métodos de comparação entre valores preditos e observados adotados para as demais variáveis, cujos resultados são expressos na Tabela 5 e na Figura 3.

Ambas as hipóteses de nulidade (8) foram nãorejeitadas para a relação obtida entre as taxas de digestão específica de CNF ( $\mathrm{P}>0,05)$ (Tabela 5). Por outro lado, observou-se relação não-coincidente $(\mathrm{P}<0,01)$ entre as taxas de digestão específica para
CF, sendo o vício global de estimação de $-12,39 \%$ para as taxas obtidas por ponderação em relação às obtidas por incubação da dieta total (Figura 3). Esses resultados confirmam a existência de efeitos de interação entre alimentos sobre a taxa de crescimento específico dos microrganismos, denotando que, embora possíveis correções sobre os parâmetros da cinética de trânsito ruminal possam ampliar a exatidão das estimativas, a avaliação de alimentos isoladamente não permite contabilizar efeitos associativos entre forragem e suplementos, notadamente sobre a taxa de digestão específica de carboidratos fibrosos.

Por outro lado, esse fenômeno interativo introduz entrave à predição de parâmetros da fermentação ruminal em bovinos suplementados em regime de pastejo. Uma vez que as taxas de digestão específicas de CF são inerentes à dieta, e não unicamente relacionadas aos alimentos (o que caracteriza processo cinético de $2^{\mathrm{a}}$ ordem), enfatiza-se a necessidade de estimativas iniciais precisas para a relação entre alimentos quanto ao total de MS consumido, o que é de difícil obtenção, haja vista a grande variabilidade observada sobre estes parâmetros em condições de campo, o que pode viciar substancialmente as estimativas.

Considerando-se as taxas de digestão específica de $\mathrm{CF}$, retorna-se à relação estimada entre valores 

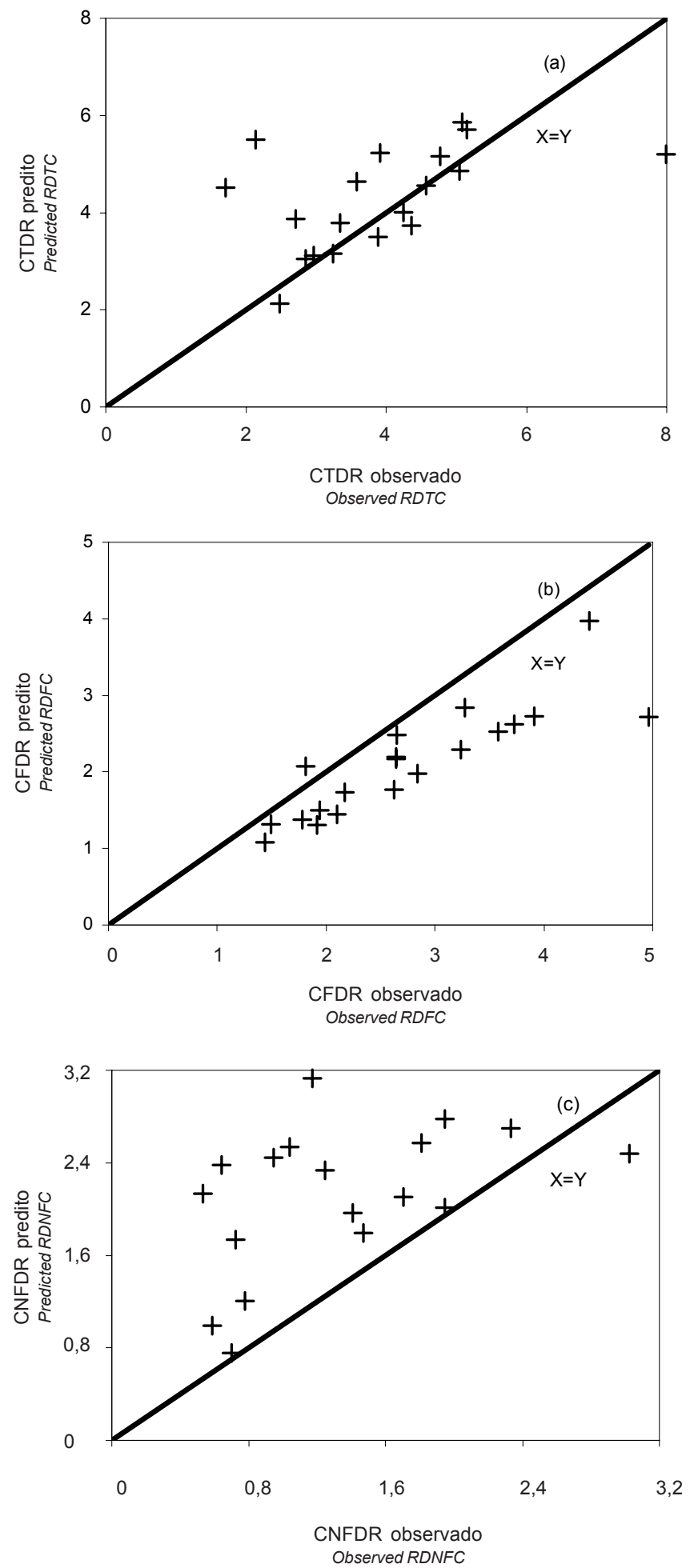

Figura 1 - Relação entre valores observados e preditos (kg/dia) para degradação ruminal dos carboidratos totais (CTDR) (a), carboidratos fibrosos (CFDR) (b) e carboidratos não-fibrosos (CNFDR) (c).

Figure 1 - Relationship between estimated and observed values (kg/day) for ruminal degradation of total (RDTC) (a), fiber (RDFC) (b), and nonfiber (RDNFC) (c) carbohydrates.
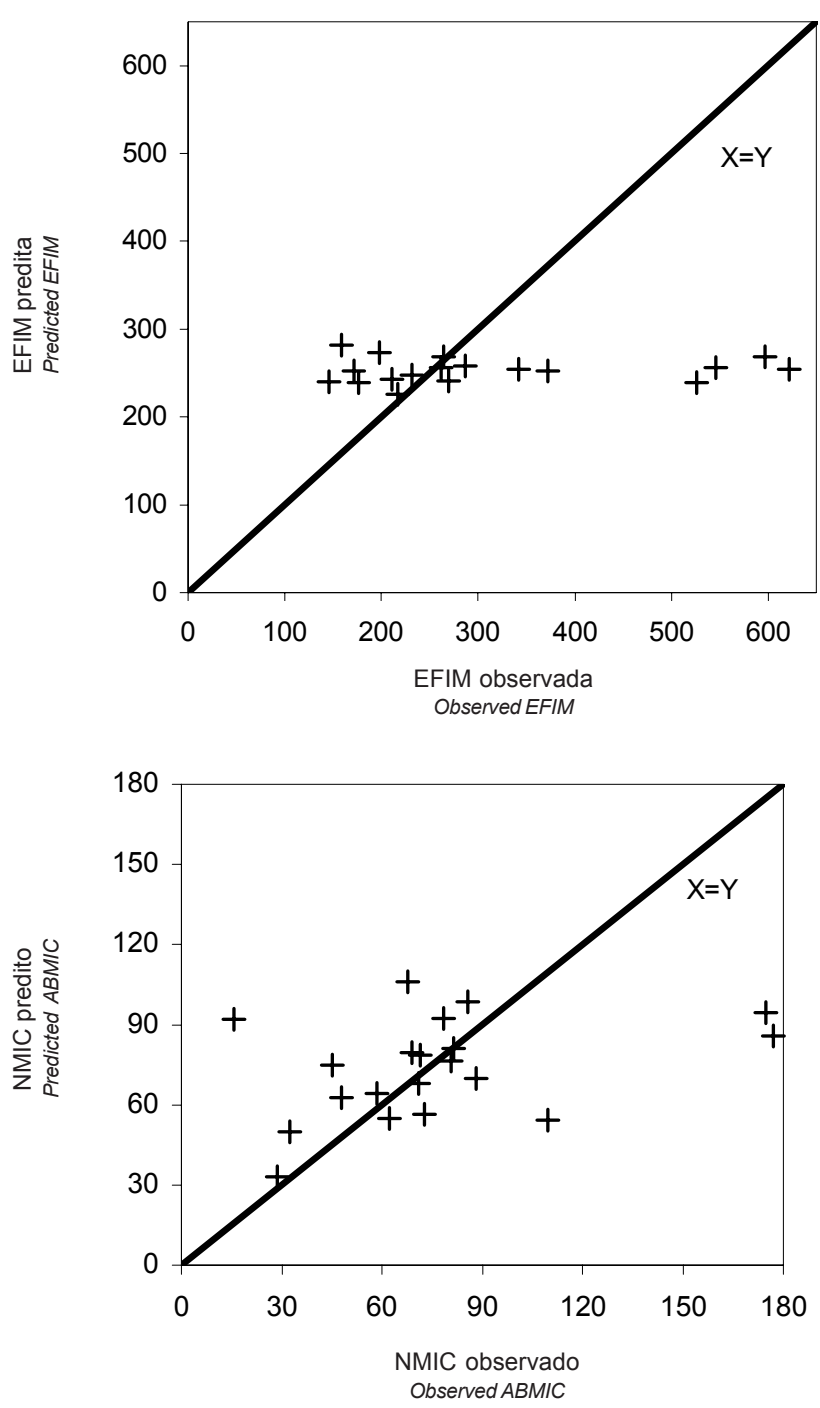

Figura 2 - Relação entre valores observados e preditos para eficiência de síntese microbiana (EFIM) (g MS microbiana/kg CTDR) e fluxo abomasal de nitrogênio microbiano (NMIC) (g/dia).

Figure 2 - Relationship between observed and predicted values for efficiency of microbial synthesis (EFIM) (g of microbial DM/kg RDTC) and abomasum flow of microbial nitrogen (ABMIC) (g/day).

preditos e observados para CFDR. A adoção da taxa conjunta permitiria elevação substancial sobre os valores preditos de CFDR, constituindo importante fator de contribuição ao quadro de subestimação observado sobre esta variável.

Comportamento similar à EFIM foi observado sobre a variável NMIC (Tabela 4). Embora tenha-se quantificado vício global de $-20,25 \%$, o coeficiente de inclinação obtido para o modelo completo não diferiu estatisticamente de zero $(\mathrm{P}>0,10)$, não se estabele- 
Tabela 5 - Estimativas de parâmetros, níveis descritivos de probabilidade para as hipóteses de nulidade e coeficientes de determinação $\left(r^{2}\right)$ para as regressões entre taxas de digestão específica para carboidratos não-fibrosos (KCNF) e carboidratos fibrosos (KCF) obtidas com a dieta completa (X) e por projeção ponderada das estimativas de alimentos individuais $(Y)$

Table 5 - Parameters estimates, descriptive levels of probability for null hypothesis, and coefficient of determination $\left(r^{2}\right)$ for the regression models between specific digestion rates for nonfiber (KNFC) and fiber (KFC) carbohydrates obtained by incubation of complete diet $(X)$ or weighed estimates from data of individual feeds

\begin{tabular}{|c|c|c|c|c|c|c|}
\hline \multirow[b]{3}{*}{ Item } & \multicolumn{4}{|c|}{$\begin{array}{l}\text { Modelo completo } \\
\text { Complete model }\end{array}$} & \multirow[b]{3}{*}{$r^{2}$} & \multirow[b]{3}{*}{$\begin{array}{l}\text { Vício globa } \\
\text { Overall bias }\end{array}$} \\
\hline & \multicolumn{2}{|c|}{$\begin{array}{l}\text { Intercepto } \\
\text { Intercept }\end{array}$} & \multicolumn{2}{|c|}{$\begin{array}{l}\text { Coeficiente de inclinação } \\
\text { Slope coefficient }\end{array}$} & & \\
\hline & $\begin{array}{l}\text { Estimativa } \\
\text { Estimate }\end{array}$ & $\begin{array}{l}\text { Valor-P1 } \\
P \text {-Value } \\
\end{array}$ & $\begin{array}{c}\text { Estimativa } \\
\text { Estimate }\end{array}$ & $\begin{array}{l}\text { Valor-P2 }^{2} \\
\text { P-Value }^{2}\end{array}$ & & \\
\hline $\begin{array}{l}\mathrm{KCNF}^{3} \\
K N F C^{3}\end{array}$ & $-0,0289$ & 0,3422 & 1,2013 & 0,3224 & 0,7280 & - \\
\hline $\begin{array}{l}\mathrm{KCF}^{3} \\
\mathrm{KFC}^{3}\end{array}$ & 0,0255 & 0,0008 & 0,0421 & 0,0003 & 0,0032 & $-12,39 \%$ \\
\hline
\end{tabular}

${ }^{1} \mathrm{H}_{0}: \beta_{0}=0 ;{ }^{2} \mathrm{H}_{0}: \beta_{1}=1 ;{ }^{3} \mathrm{~h}^{-1}$.
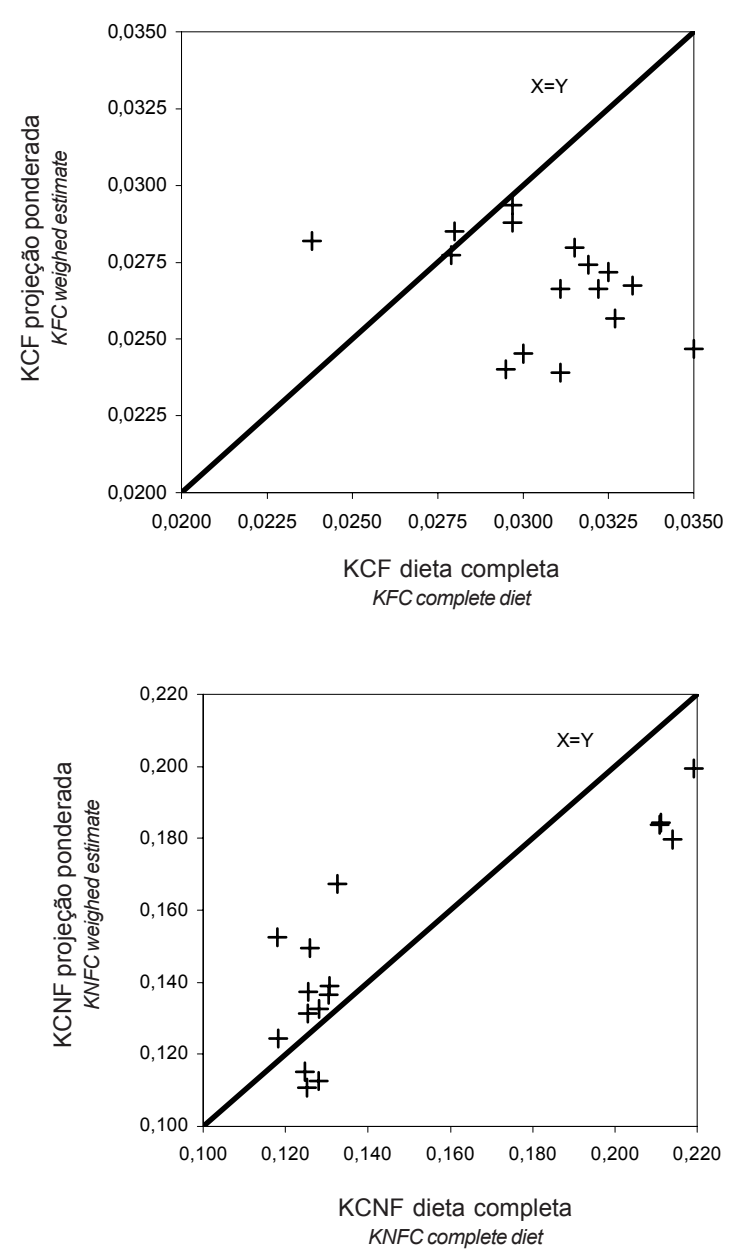

Figura 3 - Relação entre taxas de digestão específicas $\left(\mathrm{h}^{-1}\right)$ de carboidratos fibrosos (KCF) e nãofibrosos (KCNF), obtidas a partir da incubação de dieta completa e por projeção ponderada das estimativas de alimentos individuais.

Figure 3 - Relationship between specific digestion rates $\left(h^{-1}\right)$ of fiber (KFC) and nonfiber (KNFC) carbohydrates obtained by incubation of total diet or weighted estimates of individual feeds. cendo, desta forma, relação alguma entre valores preditos e observados, havendo, no entanto, de forma não esperada, elevada similaridade entre valores médios preditos e observados para esta variável (Tabela 3 ). Esses resultados refletem, indiretamente, a incapacidade de simulação de variações ou flutuações naturais desses parâmetros como resposta a estímulos alimentares diferenciados, o que pode ser evidenciado pela tendência desta variável.

\section{Conclusões}

A utilização da técnica de produção de gases para estimação de parâmetros da fermentação ruminal resulta em sub e superestimativas da degradação ruminal de carboidratos fibrosos e não-fibrosos, respectivamente.

Embora possíveis correções sobre os processos de estimação dos parâmetros da cinética de trânsito ruminal possam ampliar a exatidão das estimativas, a avaliação de alimentos isoladamente não permite contabilizar efeitos associativos entre forragem e suplementos, notadamente sobre a taxa específica de digestão dos carboidratos fibrosos.

\section{Literatura Citada}

ALLEN, M.S.; MERTENS, D.R. Evaluating constraints on fiber digestion by rumen microbes. Journal of Nutrition, v.118, n.1, p.261-270, 1988.

ASSOCATION OF OFFICIAL ANALYTICAL CHEMISTRY AOAC. Official methods of analysis. 15.ed. Arlington: AOAC International, 1990. $1117 \mathrm{p}$.

BÜRGER, P.J.; PEREIRA, J.C.; COELHO DA SILVA, J.F. et al. Taxas de passagem e cinética da degradação ruminal em bezerros holandeses alimentados com dietas contendo diferentes níveis 
de concentrado. Revista Brasileira de Zootecnia, v.29, n.1, p.225-235, 2000 .

CABRAL, L.S.; VALADARES FILHO, S.C.; MALAFAIA, P.A.M. et al. Frações de carboidratos de alimentos volumosos e suas taxas de degradação estimadas pela técnica de produção de gases. Revista Brasileira de Zootecnia, v.29, n.6, p.2087-2098 (Suplemento 1), 2000.

CECAVA, J.M.; MERCHEN, N.R.; GAY, L.C. et al. Composition of ruminal bacteria harvested from steers as influenced by dietary energy level, feeding frequency, and isolation techniques. Journal of Dairy Science, v.73, p.2480-2488, 1990.

COCHRAN, W.G.; COX, G.M. Experimental designs. 2.ed. New York: Jonh Willey \& Sons, 1957. 611p.

COLUCCI, P.E.; MacLEOD, G.K.; GROVUM, W.L. et al. Digesta kinetics in sheep and cattle fed diets with different forage to concentrate ratios at low and high intakes. Journal of Dairy Science, v.73, n.8, p.2143-2156, 1990

DETMANN, E.; CECON, P.R.; PAULINO, M.F. et al. Estimação de parâmetros da cinética de trânsito de partículas em bovinos sob pastejo por diferentes seqüências amostrais. Revista Brasileira de Zootecnia, v.30, p.222-230, 2001.

DETMANN, E.; PAULINO, M.F.; CECON, P.R. et al. Níveis de proteína em suplementos para terminação de bovinos em pastejo durante o período de transição seca/águas: Consumo voluntário e trânsito de partículas. Revista Brasileira de Zootecnia, v.34, n.4, p.1371-1379, 2005.

DJKISTRA, J.; FRANCE, J.; NEAL, H.D.C. et al. Simulation of digestion in cattle fed sugarcane: model development. Journal of Agricultural Science, v.127, n.1, p.231-246, 1996

FRANCE, J.; DHANOA, M.S.; SIDDONS, R.C. et al. Estimating the fecal producing by ruminants from faecal marker concentration curves. Journal of Theoretical Biology, v.135, n.2, p.383-391, 1988.

HESS, B.W.; PARK, K.K.; KRYSL, L.J. et al. Supplemental protein for beef cattle grazing dormant intermediate wheatgrass pasture: effects on nutrient quality, forage intake, digesta kinetics, grazing behavior, ruminal fermentation, and digestion. Journal of Animal Science, v.72, p.2113-2123, 1994.

HUHTANEN, P.; JAAKKOLA, S.; KUKKONEN, U. Ruminal plant cell wall digestibility estimated from digestion and passage kinetics utilizing mathematical models. Animal Feed Science and Technology, v.52, n.1, p.159-173, 1995.

LIPPKE, H.; ELLIS, W.C.; JACOBS, B.F. Recovery of indigestible fiber from feces of sheep and cattle on forage diets. Journal of Dairy Science, v.69, p.403-412, 1986.

MALAFAIA, P.A.M.; VALADARES FILHO, S.C.; VIEIRA, R.A.M. et al. Cinética ruminal de alguns alimentos investigados por técnicas gravimétricas e metabólicas. Revista Brasileira de Zootecnia, v.27, n.2, p.370-380, 1998.

McDOUGALL, E.I. Studies on ruminal saliva. 1.The composition and output of sheep's saliva. Biochemistry Journal, v.43, n.1, p.99-109, 1949.

MERTENS, D.R. Regulation of forage intake. In: FAHEY JR., G.C. (Ed.) Forage quality, evaluation and utilization. Winsconsin: American Society of Agronomy, 1994. p.450-493.

NOCEK, J.E.; RUSSELL, J.B. Protein and energy as an integrated system. Relation of ruminal protein and carbohydrates availability to microbial synthesis and milk production. Journal of Dairy Science, v.71, n.8, p.2070-2107, 1988.
NATIONAL RESEARCH COUNCIL - NRC. Nutrient requirements of dairy cattle. 7.ed. Washington: Academic Press, 2001. 381p.

OBA, M.; ALLEN, M.S. Evaluation of the importance of the digestibillity of neutral detergent fiber from forage: effects on dry matter intake and milk yield of dairy cows. Journal of Dairy Science, v.82, n.3, p.589-596, 1999.

PELL, A.N.; SCHOFIELD, P. Computerized monitoring of gas production to measure forage digestion in vitro. Journal of Dairy Science, v.76, n.4, p.1063-1073, 1993.

PIRT, S.J. The maintenance energy of bacteria in growing cultures. Proceedings of Royal Society (Series B), n.163, p.224-231, 1965.

RAYBURN, E.B.; FOX, D.G. Variation in neutral detergent fiber intake of holstein cows. Journal of Dairy Science, v.76, n.3, p.544-554, 1993.

RUSSELL, J.B.; O'CONNOR, J.D.; FOX, D.G. et al. A net carbohydrate and protein system for evaluating cattle diets: I. Ruminal fermentation. Journal of Animal Science, v.70, n.11, p.3551-3561, 1992.

SCHOFIELD, P.; PITT, R.E.; PELL, A.N. Kinetics of fiber digestion from in vitro gas production. Journal of Animal Science, v.72, n.11, p.2980-2991, 1994.

SCHOFIELD, P.; PELL, A.N. Measurement and kinetics analysis of the neutral detergent-soluble carbohydrates fraction of legumes and grasses. Journal of Animal Science, v.73, n.12, p.3455-3463, 1995.

SNIFFEN, C.J.; O'CONNOR, J.D.; Van SOEST, P.J. et al. A net carbohydrate and protein system for evaluating cattle diets: II.Carbohydrate and protein availability. Journal of Animal Science, v.70, n.11, p.3562-3577, 1992.

UDÉN, P.; COLUCCI, P.E.; Van SOEST, P.J. Investigation of chromium, cerium and cobalt as markers in digesta. Rate of passage studies. Journal of Science and Food Agriculture, v.31, p.625-632, 1980.

USHIDA, K.; LASSALAS, B.; JOUANY, J.P. Determination of assay parameters for RNA analysis in bacterial and duodenal samples by spectrophotometry. Influence of treatment and preservation. Reproduction and Nutrition Development, v.25, p.1037-1046, 1985.

Van SOEST, P.J. Nutritional ecology of the ruminant. Ithaca: Cornell University Press, 1994. 476p.

Van SOEST, P.J.; ROBERTSON, J.B. Analysis of forages and fibrous foods. Ithaca: Cornell University, 1985. 202p.

VIEIRA, R.A.M.; PEREIRA, J.C.; MALAFAIA, P.A.M. et al. Simulação da dinâmica de nutrientes no trato gastrintestinal: aplicação e validação de um modelo matemático para bovinos a pasto. Revista Brasileira Zootecnia, v.29, n.3, p.898-909, 2000.

WILLIANS, C.H.; DAVID, D.J.; IISMA, O. The determination of chromic oxide in faeces samples by atomic absorption spectrophotometry. Journal of Agricultural Science, v.59, p.381-385, 1962. 